\title{
The influence of the opening angle of conductor surface on the drag
}

\section{coefficient}

\author{
LIU Zhen ${ }^{1, a}$, WANG Zhao-lin ${ }^{1, a}$, ZHU Kuang-jun ${ }^{1,}$ a , ZHOU Li-xian ${ }^{1, \text { a }}$, \\ 1China Electric Power Research Institute, Beijing 102401, China \\ a liuzhen@epri.sgcc.com.cn a877424770@qq.com

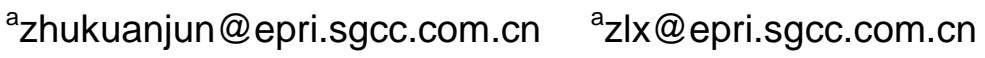

Key words: Steel core aluminum wire; Wind resistance coefficient; Opening angle

Abstract: In this paper, the wind resistance coefficient of low-pressure steel core aluminum wire with different opening angle is measured by wind tunnel test under different wind speed conditions. The results show that when the wind speed is below $35 \mathrm{~m} / \mathrm{s}$, the wind resistance coefficient of the wires with different structural forms is large. When the wind speed is above $35 \mathrm{~m} / \mathrm{s}$, the drag coefficient of the ordinary ACSR is the largest, followed by the steel core forming aluminum stranded wire.In the four open-angle wires, the overall drag resistance coefficient decreases as the opening angle increases, and the drag coefficient of the corresponding conductor is the smallest when the opening angle is $90^{\circ}$.

\section{Introduction}

At present, the low wind pressure wire is mainly used as a special functional conductor, which can be used to reduce the wind load. By changing the surface structure of the wire to change the flow field characteristics, so as to achieve the purpose of reducing wind pressure.

Research and development of low pressure wire, by changing the properties of the wire itself can reduce the wind's goal is a very effective way, has a wide application prospect in practice. At the same time, the application of low wind pressure wire in the general area can greatly reduce the structural design load, thereby reducing the cost of line construction, greatly saving investment, application prospects and great economic benefits.

Japanese scholar Sakakibara found that the wind resistance characteristics of conductor shown, its surface roughness is an important relationship between, the roughness of the larger wire can be showed the lowest resistance coefficient to the "critical Reynolds number" is bigger, whereas the smaller.

Based on the conventional ACSR JL/G1A-630/45-45/7 design of a steel core aluminum stranded wire forming and 4 in accordance with the principle of equal diameter and different opening angle design of four kinds of low pressure wire, the opening angle is shown in Figure 1, and the comparison between the wind tunnel test is carried out. Under the different wind speed, the wind resistance coefficient of several kinds of steel cored aluminum strand is changed with the opening angle. 


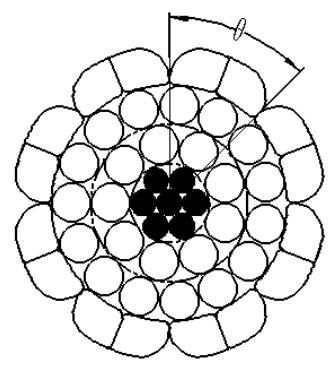

Figure 1. Schematic diagram of the opening angle

\section{wire structure design}

Based on the conventional ACSR JL/G1A-630/45-45/7 design of a steel core aluminum stranded wire forming and 4 in accordance with the principle of equal diameter and different opening angle (30 degrees, 45 degrees, 60 degrees and 90 degrees) designed four kinds of low pressure wire. In order to facilitate the test, the 6 wires are numbered as follows:

JLX1/G1A (DFY) -675/45 (30) -33.75, known as the No. 1 line; JLX1/G1A-630/45-33.75, known as the No. 2 line; JLX1/G1A (DFY) -675/45 (45) -33.75, known as the No. 3 line; JLX1/G1A (DFY) -675/45 (60) -33.75, known as the No. 4 line; JLX1/G1A (DFY) -675/45 (90 degrees -33.75), known as the No. 5 line; JL/G1A-630/45-33.75, known as the No. 6 line. The cross section of the sample is shown in Figure 2 and the sample is shown in figure 3.

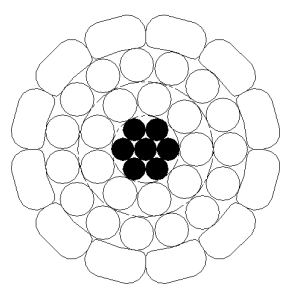

JLX1/G1A(DFY)-675/45(30)-33.75

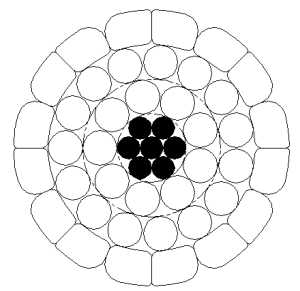

JLX1/G1A(DFY) $-675 / 45\left(45^{\circ}\right)-33.75$

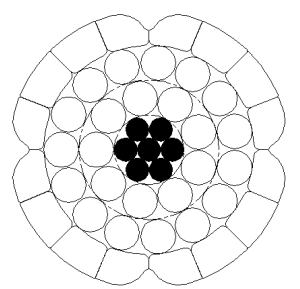

JLX1/G1A（DFY）-675/45(90) $-33.75$

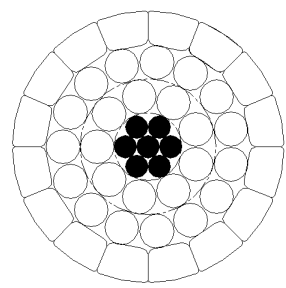

JLX1/G1A-630/45-33.75

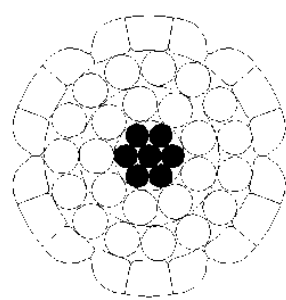

JLX1/G1A(DFY)-675/45 (60 $)-33.75$

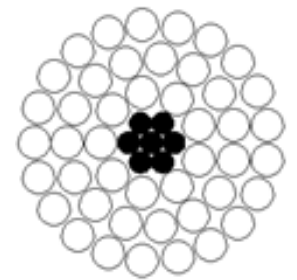

JL/G1A-630/45-33.75

Figure 2. Sketch of cross section 


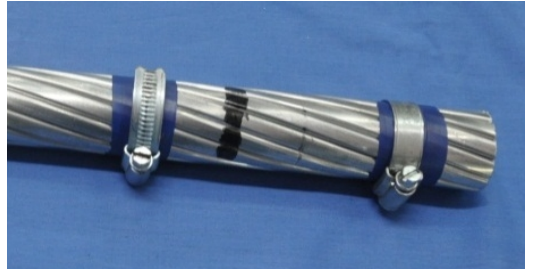

JLX1/G1A（DFY）-675/45(30) -33.75

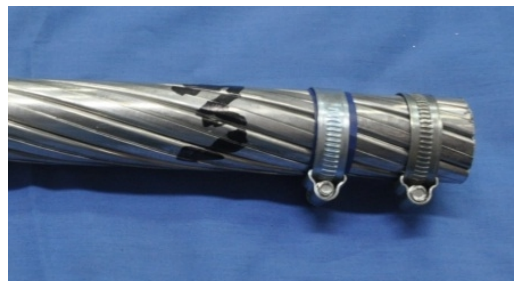

JLX1/G1A（DFY） $-675 / 45\left(45^{\circ}\right)-33.75$

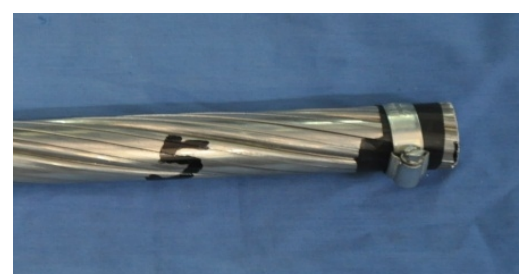

JLX1/G1A（DFY） $-675 / 45\left(90^{\circ}\right)-33.75$

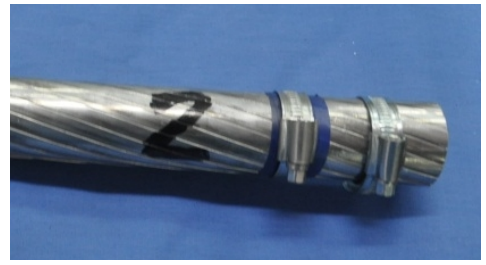

JLX1/G1A-630/45-33.75

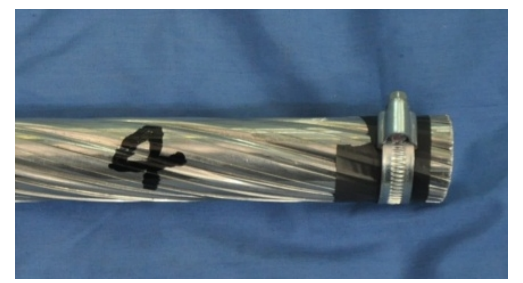

JLX1/G1A（DFY） -675/45(60º)-33.75

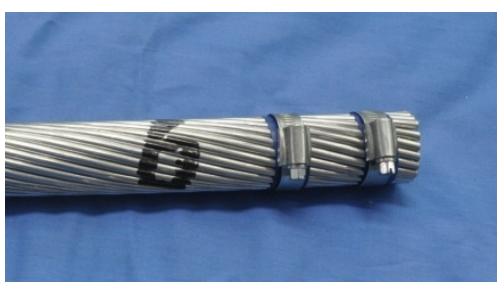

JL/G1A-630/45-33.75

Figure 3. Specimen physical map

\section{wind tunnel test}

\section{Test conditions}

The wind tunnel test was carried out to investigate the performance of the 6-conductor resistance wind pressure and the effect of different opening angles on the drag coefficient of the wire. Wind tunnel test in the Nanjing University of Aeronautics and Astronautics Institute of Aerodynamics Institute completed the wind tunnel. The wind tunnel test section size of $3 \mathrm{~m} \times 2.5 \mathrm{~m} \times 6 \mathrm{~m}$, can produce $5 \sim 90 \mathrm{~m} / \mathrm{s}$ continuous wind speed. Considering the wind speed in the strong wind area, the wind speed of $20 \mathrm{~m} / \mathrm{s}, 30 \mathrm{~m} / \mathrm{s}, 40 \mathrm{~m} / \mathrm{s}, 50 \mathrm{~m}$ $/ \mathrm{s}, 60 \mathrm{~m} / \mathrm{s}$ and $70 \mathrm{~m} / \mathrm{s}$ in the uniform flow field is tested. The T-1 tower six-component balance was used to measure the wire resistance. Figure 4 is the wind tunnel test wire sample layout, including the wire and the incoming angle of $90^{\circ}$ and $60^{\circ}$ two conditions.

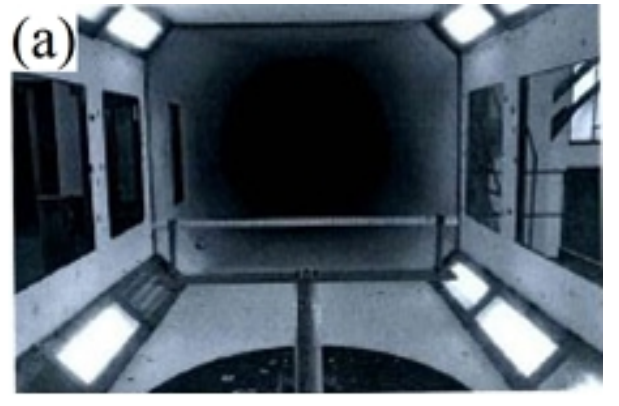

(a) The angle between the conductor and the incoming flow is 90 degrees

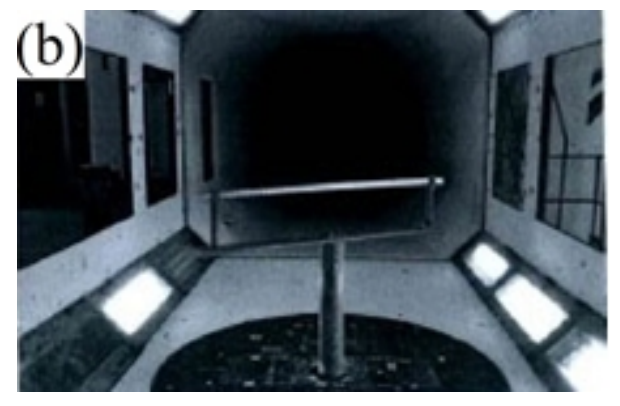

(b) the angle between the conductor and the current is 60 degrees.

Figure 4. The layout of wire sample in wind tunnel test 


\section{wind resistance calculation}

During the test, the vertical direction of the support was kept, and the resistance of the support was measured. After installing the wire, measure all resistance. In data processing, the resistance of the wire is less than that of all the resistance measured by the latter. And then the whole wind resistance coefficient is calculated by formula (1):

In the formula: $\mathrm{Cd}$-per unit length of wire wind resistance coefficient; $\mathrm{F}$-the wind resistance wire $(\mathrm{kg})$; $\rho$ - air density $(\mathrm{kg} / \mathrm{m} 3)$; V- wind speed (m/s; D-for wind the wire diameter $(\mathrm{m})$; L -the wire length $(\mathrm{m})$.

\section{test results}

Tables 1 and 2 are given coefficient of drag per unit length respectively of the wire at different wind speed when wire and current angle was 90 degrees and 60 degrees, figure 5 and figure 6 are given wind resistance coefficient changes with wind speed when The angle between the wire and the incoming streamwas 90 degrees and 60 degrees.

Table 1 The drag coefficient per unit length of conductors under various wind speeds (the angle between the conductor and the inflow is 90 degrees)

\begin{tabular}{ccccccc}
\hline Wind speed $(\mathrm{m} / \mathrm{s})$ & $1 \#$ & $2 \#$ & $3 \#$ & $4 \#$ & $5 \#$ & $6 \#$ \\
\hline 20 & 1.08 & 1.12 & 1.08 & 0.98 & 0.99 & 0.98 \\
30 & 0.94 & 0.94 & 0.91 & 0.93 & 0.82 & 1.06 \\
40 & 0.83 & 0.88 & 0.83 & 0.82 & 0.80 & 0.94 \\
50 & 0.87 & 0.90 & 0.88 & 0.83 & 0.81 & 0.98 \\
60 & 0.89 & 0.90 & 0.86 & 0.85 & 0.81 & 0.96 \\
70 & 0.91 & 0.91 & 0.88 & 0.87 & 0.82 & 0.99 \\
\hline
\end{tabular}

Table 2 The drag coefficient per unit length of conductors under various wind speeds (the angle between the conductor and the inflow is 60 degrees)

\begin{tabular}{ccccccc}
\hline Wind speed $(\mathrm{m} / \mathrm{s})$ & $1 \#$ & $2 \#$ & $3 \#$ & $4 \#$ & $5 \#$ & $6 \#$ \\
\hline 20 & 0.58 & 0.62 & 0.53 & 0.61 & 0.61 & 0.62 \\
30 & 0.62 & 0.59 & 0.58 & 0.59 & 0.61 & 0.64 \\
40 & 0.59 & 0.59 & 0.58 & 0.55 & 0.53 & 0.64 \\
50 & 0.60 & 0.61 & 0.57 & 0.56 & 0.54 & 0.66 \\
60 & 0.61 & 0.62 & 0.60 & 0.57 & 0.54 & 0.67 \\
70 & 0.63 & 0.65 & 0.62 & 0.58 & 0.53 & 0.67 \\
\hline
\end{tabular}




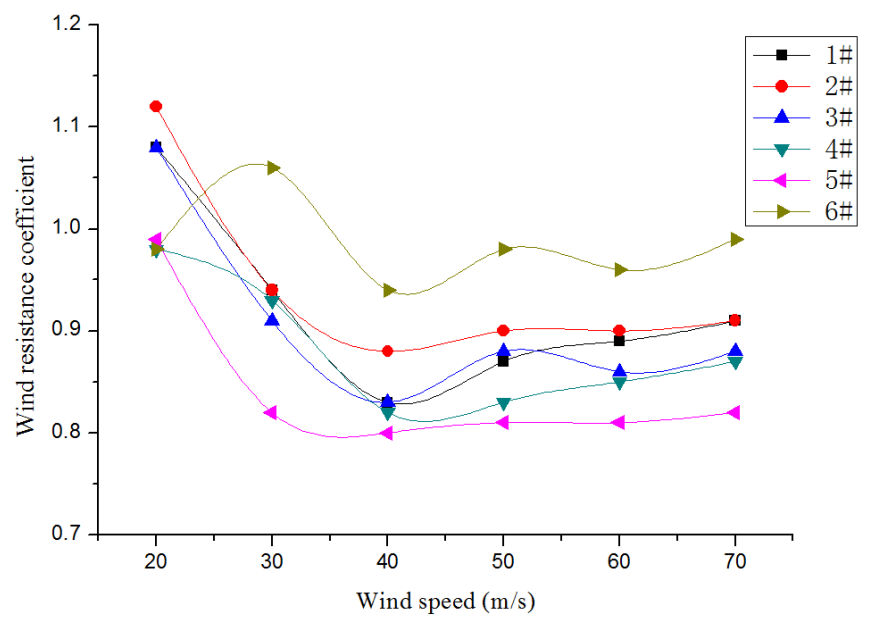

Figure 5. wind resistance coefficient curve of conductor with wind speed (conductor perpendicular to flow)

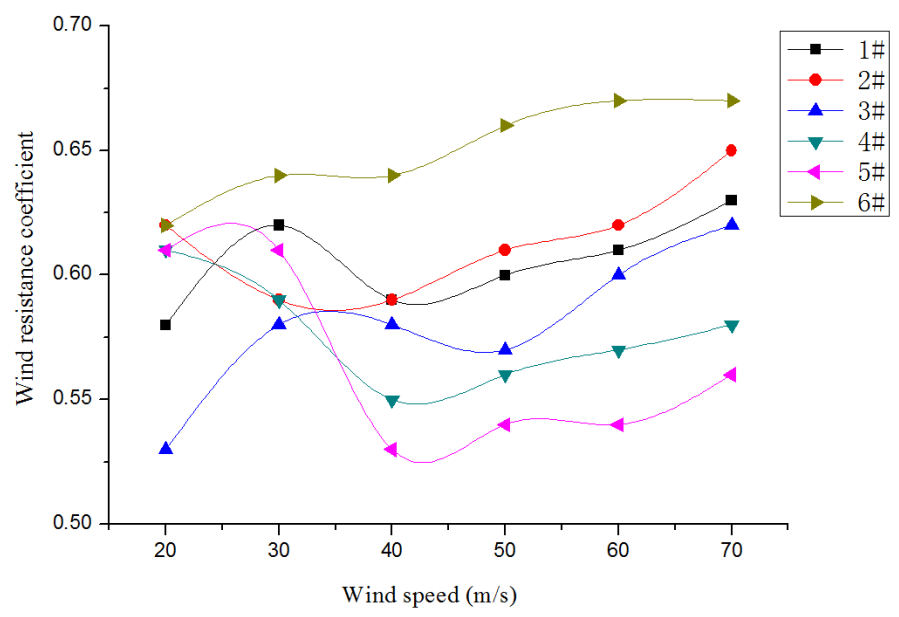

Figure 6. coefficient of drag coefficient of wind speed variation of each conductor (60 degrees between conductor and inflow)

Figure 5 and figure 6 shows that when the wind speed is below $35 \mathrm{~m} / \mathrm{s}$, the wind resistance coefficient of the wires with different structural forms is large. When the wind speed is above $35 \mathrm{~m} / \mathrm{s}$, the drag coefficient of the ordinary ACSR is the largest, followed by the steel core forming aluminum stranded wire.In the four open-angle wires, the overall drag resistance coefficient decreases as the opening angle increases, and the drag coefficient of the corresponding conductor is the smallest when the opening angle is $90^{\circ}$.

\section{conclusion}

(1) based on the common ACSR JL/G1A-630/45-33.75, JLX1/G1A-630/45-33.75 was Designed according to the design principle of diameter. At the same wind speed, the drag coefficient of the surface is smaller than ordinary steel core aluminum wire.

(2) when the wind speed range is $35 \mathrm{~m} / \mathrm{s}$, the wire surface structure has little effect on the drag coefficient.

(3) when the wind speed range of 35 70m/s,the opening angle of twisted pair wire surface has great influence on wind resistance coefficient, the drag coefficient decreases with the increase of the open angle, therefore, Therefore, by increasing the opening angle can reduce the special steel core type of wire strand wind resistance coefficient. 


\section{Reference}

[1] Japan Electric Cooperative Research Association. Research on the new type of Lead electrical coordination [J]. (43),:6-9., 1988

[2] Kikuchi Naoshi, Feng Qi song. With the low pressure electric line development of [J]. Furukawa electric overhead power transmission times, 109th, 2002 (1): 51-56.

[3] Research and development of low noise conductors in transmission lines [J]. electric power construction, 2005, 26 (9):1-5.

[4] C.Y. You, Development of reduced for transmission lines, Electric Power Construction (12) (2010) 1-6. drag conductor ()

[5] S.D. Li, Vibration analysis wind-induced overhead transmission lines, Beijing: North Electric Power University, 2014, for, of, China 